\title{
Pendampingan Penyusunan Administrasi PAUD Sekato Desa Mandiangin Kecamatan Minas Kabupaten Siak
}

\author{
Ida Windi Wahyuni ${ }^{1}$, Ary Antony Putra ${ }^{2}$ \\ 1,2 Universitas Islam Riau, Indonesia
}

\begin{abstract}
A B S T R A C T
ASSISTANCE IN PREPARING PAUD SEKATO ADMINISTRATION OF MANDIANGIN VILLAGE, MINAS DISTRICT, SIAK REGENCY. Educational administration there are several fields or elements that are interrelated with one another, namely the field of human resources, learning resources, and facilities implemented. These three elements are listed in one system which is divided into three functions, namely the planning function, the implementation function, and the supervisory function. PAUD administration assistance directs school principals, teachers and PAUD program development in carrying out technical guidance in administering PAUD institutions. The purpose of the activities to be carried out in this activity is to evaluate and arrange school administration and curriculum in PAUD Sekato as well as to assist in preparing PAUD administration. Assistance in the preparation of PAUD administration is carried out in PAUD Sekato, Mandiangin Village, Minas Subdistrict, Siak Regency, from July to August 2019. The results of this activity are the preparation of PAUD administration. Sekato Mandiangin Village only focuses on general administration, learning administration and student administration. The limitations of this assistance are due to the time, distance and available funds. The team hopes for the next program is to prepare an administrative program that has not yet been completed so that the administration of Sekato PAUD is completely arranged and can be submitted in the PAUD accreditation submission.

Keywords: Administration, Assistance, Compilation, Early Childhood, Education.

\begin{tabular}{llll}
\hline Received: & Revised: & Accepted: & Available online: \\
07.10 .2019 & 11.01 .2020 & 03.02 .2020 & 14.02 .2020 \\
\hline
\end{tabular}
\end{abstract}

\section{Suggested citation:}

Wahyuni, I. W., \& Putra, A. A. (2020). Pendampingan penyusunan administrasi PAUD Sekato Desa Mandiangin Kecamatan Minas Kabupaten Siak. Jurnal Pengabdian Pada Masyarakat, 5(1), 125132. https://doi.org/10.30653/002.202051.264

Open Access I URL: http://ppm.ejournal.id/index.php/pengabdian/article/view/264

${ }^{1}$ Corresponding Author: Prodi Pendidikan Islam Anak Usia Dini, Fakultas Agama Islam, Universitas Islam Riau, Jl. Kaharuddin Nasution No. 113 Marpoyan, Kota Pekanbaru, Indonesia. Email: idawindi@fis.uir.ac.id 


\section{PENDAHULUAN}

PAUD adalah lembaga penting yang dapat mempengaruhi perkembangan anak. PAUD didirikan bertujuan tidak hanya untuk memenuhi hak asasi seorang anak mendapatkan kesempatan pendidikan, namun juga memberikan dasar untuk pertumbuhan dan perkembangan anak dalam semua aspeknya, baik aspek ketrampilan, sosial, akademik dan moral (Rochaety, 2006, p. 32).

Peraturan Menteri Pendidikan Nasional nomor 58 tahun 2009 tentang standar PAUD, yang kemudian direvisi menjadi Peraturan Menteri Pendidikan Nasional nomor 137 tahun 2014 tentang standar PAUD yang terdiri atas (1) Standar Tingkat Pencapaian Perkembangan Anak Usia Dini selanjutnya disebut STPPA; (2) Standar Isi; (3) Standar Proses; (4) Standar Penilaian; (5) Standar Pendidik dan Tenaga Kependidikan; (6) Standar Sarana Prasana; (7) Standar Pengelolaan; dan (8) Standar Pembiayaan. Standar PAUD diharapkan menjadi standar acuan minimal bagi masyarakat dan stakeholders dalam memberikan pelayanan pendidikan yang berkualitas bagi anak usia dini (Kasrani, 2016).

Pendidikan anak usia dini merupakan pondasi untuk menciptakan sumber daya manusia yang unggul dan bermartabat. Oleh karena itu, PAUD merupakan salah satu prioritas dalam pembangunan pendidikan di Indonesia. Tujuan Pendidikan anak usia dini adalah untuk mengembangkan potensi anak sejak dini dan sebagai persiapan dalam hidup serta dapat menyesuaikan diri dengan lingkungannya (Susilo, 2016). Pentingnya lembaga PAUD dalam pembentukan pondasi dan dasar kepribadian sebagai penentu pengalaman anak selanjutnya (Agustina, 2010).

Pengelolaan PAUD berorientasi pada kebutuhan, yaitu pendidikan yang berdasarkan dengan minat, kebutuhan dan kemampuan atau potensi sang anak. Peran pengelola PAUD hendaklah mampu memberikan fasilitas dengan segala aktivitas anak dan dengan berbagai kelengkapan yang beraneka ragam dalam menunjang segala kebutuhan dalam perkembangannya (Saputra, 2016). Pengelolaan PAUD meliputi: program kegiatan belajar, siswa, pegawai, biaya, sarana dan prasarana, tata usaha, organisasi dan hubungan sekolah dengan masyarakat (Wijayanti, 2008)

Administrasi pendidikan terdapat beberapa bidang atau unsur yang saling berkaitan antara satu dengan yang lainnya, yaitu bidang sumberdaya manusia, sumber belajar, dan fasilitas yang dilaksanakan. Ketiga unsur tersebut tercantum dalam satu system yang terbagi dalam tiga fungsi, yakni fungsi perencanaan, fungsi pelaksanaan, dan fungsi pengawasan.

Pendampingan administrasi PAUD mengarahkan kepala sekolah, dan guru serta pembinaan program PAUD dalam melaksanakan pembinaan teknis penyelenggaraan administrasi lembaga PAUD. Penyusunan administrasi dilakukan disesuaikan dengan kebutuhan lembaga PAUD itu sendiri, yaitu perencanaan, pelaksanaan, dan evaluasi. Perencanaan pembelajaran di Lembaga PAUD diuraikan dalam Rencana Pelaksanaan Pembelajaran Harian (RPPH), Rencana Pelaksanaan Pembelajaran Mingguan (RPPM), Progranm Semester (Promes), dan Program Tahunan (Prota). Adapun pengelolaan administrasi PAUD menyediakan administrasi yang efektif dan efisien dalam menunjang PAUD untuk kemajuan PAUD sesuai dengan ketentuan yang ada.

Secara umum, administrasi adalah suatu proses yang pada umumnya terdapat pada semua usaha kelompok, negeri maupun swasta, sipil maupun militer, usaha besar 
maupun kecil. Sedangkan secara khusus, administrasi adalah kegiatan mencatat, surat menyurat, pembukuan ringan, ketik mengetik dan agenda lainnya yang bersifat ketatausahaan (Widiani, 2016). Administrasi bersifat praktis, agar dapat dikerjakan sesuai situasi dan kondisi program PAUD.

Pendampingan yang dilaksanakan oleh Tim Program Studi Pendidikan Islam Anak Usia Dini Fakultas Agama Islam Universitas Islam Riau merupakan bentuk kepedulian antara sebuah bersama pendidikan terhadap pendidikan, khususnya Pendidikan Anak Usia Dini. Kepedulian itu diwujudkan dalam bentuk pendampingan penyusunan administrasi PAUD pada salah satu bersama pendidikan di Desa Mandiangin Kecamatan Minas Kabupaten Siak, yaitu PAUD Sekato.

Pemilihan lokasi kegiatan berdasarkan hasil observasi pada bulan Desember 2018 bahwa PAUD Sekato masih sangat sederhana dalam pengelolaan pengembangan administrasi PAUD. Adiministrasi dan kurikulum masih belum lengkap. Kegiatan ini dilaksanakan sepenuhnya oleh dosen dan mahasiswa Program Studi Pendidikan Islam Anak Usia Dini Fakultas Agama Islam yang dikoordinir oleh Lembaga Penelitian dan Pengabdian Masyarakat (LPPM) Universitas Islam Riau.

Tujuan kegiatan yang akan dilakukan dalam kegiatan ini adalah untuk mengevaluasi dan menyusun administrasi sekolah dan kurikulum di PAUD Sekato serta melakukan pendampingan dalam menyusun administrasi PAUD. Hasil pendampingan ini dapat dimanfaatkan oleh guru-guru PAUD dalam pengembangan dan peningkatan kualitas PAUD Sekato di Desa Mandiangin Kecamatan Minas Kabupaten Siak.

\section{METODE}

Pelaksanaan Pengabdian kepada Masyarakat (PkM) oleh tim dilakukan di PAUD Sekato Desa Mandiangin Kecamatan Minas Kabupaten Siak Provinsi Riau, pada bulan Juli-Agustus 2019. Tim yang dibantu mahasiswa melakukan briefing dengan mitra untuk menindaklanjuti kegiatan pengabdian ini. Selanjutnya, tim menyerahkan surat perizinan dari LPPM UIR sebagai syarat administrasi pelaksanaan kegiatan.

Sasaran pelaksanaan kegiatan, yakni guru-guru PAUD Sekato. Kepala Sekolah dan Guru PAUD Sekato Desa Mandiangin berjumlah 2 orang. Kepala Sekolah dan Guru PAUD Sekato adalah lulusan SMA. Pengalaman tentang pengelolaan PAUD hanya diperoleh dari pelatihan-pelatihan tingkat kecamatan atau kabupaten di Kabupaten Siak. Belum adanya guru yang lulusan sarjana sehingga pengetahuan dan pemahamannya mengenai pengelolaan PAUD masih sangat minim.

Metode yang diterapkan dalam pengabdian kepada masyarakat ini adalah Society Parcipatory, yaitu guru PAUD sebagai mitra dapat menyerap pemahaman serta wawasan mengenai adminstrasi PAUD melalui pendampingan yang dilakukan oleh Tim dari Program Studi PIAUD FAI UIR. Pelaksanaan pendampingan administrai PAUD akan dititikberatkan kepada pendampingan penyusunan administrasi sekolah dan pengelolaan pembelajaran. Hal ini dilakukan atas dasar observasi awal, dimana belum tertibnya administrasi sekolah, penyusunan RPPH, RPPM, PROSEM dan PROTA yang sesuai dengan kebijakan PAUD yang telah ditetapkan oleh Dinas Pendidikan. 
Tim tutor yang dibantu mahasiswa memberikan pendampingan secara langsung penyusunan administrasi PAUD. Mahasiswa menelaah dan mengklasifikasi bagian mana yang harus dipersiapkan terlebih dahulu. Mitra dengan senang dan semangat bekerjasama dalam proses penyusunan tersebut.

Program-program yang telah terlaksana dengan baik dengan indikator keberhasilannya adalah

1) Administrasi PAUD Sekato telah tersusun dengan rapi sesuai pedoman yang telah ditetapkan oleh Kementrian Pendidikan Nasional.

2) Guru PAUD telah paham dan dapat mempraktekkan penyusunan RPPH, RPPM, PROSEM dan PROTA dengan baik dan benar.

3) Peningkatan kualitas dan kuantitas tentang administrasi PAUD guna menciptakan iklim kerja yang kondusif.

\section{HASIL DAN PEMBAHASAN}

Pelaksanaan program kegiatan ini dimulai pada Bulan Juli sampai dengan Agustus 2019. Observasi kegiatan ini dilakukan dengan bertahap. Tahap pertama kunjungan awal pada bulan Desember 2018 dengan melakukan pendekatan melalui Penghulu Kampung Mandiangin. Kemudian, Penghulu merekomendasikan kepada Kepala PAUD Sekato sebagai mitra utama pelaksanaan kegiatan pengabdian masyarakat Prodi PIAUD FAI UIR. Tahap kedua, yakni melakukan perizinan dan informasi pelaksanaan program dengan menyampaikan surat perizinan yang ditandatangi oleh ketua LPPM UIR.

Hasil observasi awal menyimpulkan bahwa adminitrasi PAUD Sekato masih sangat sederhana. Wawancara yang dilakukan terhadap kepala sekolah mengungkapkan bahwa administrasi tersebut disusun berdasarkan hasil pelatihan yang pernah diikuti di tingkat kecamatan dan kabupaten. Hal inilah yang menjadi prioritas utama tim dalam pengabdian ini.

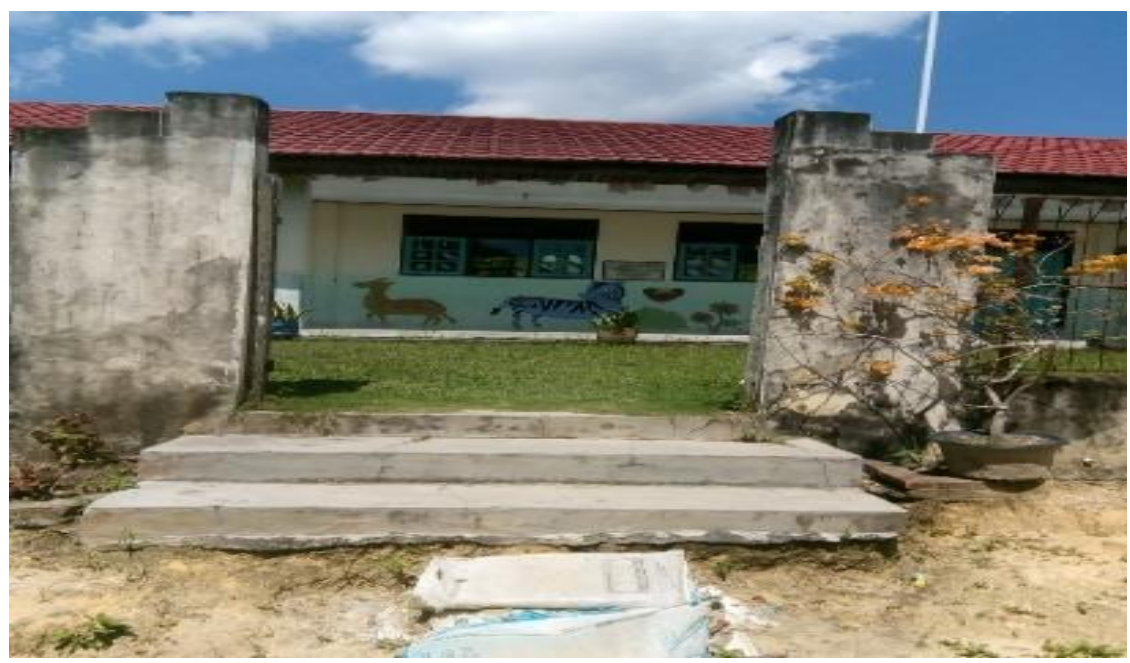

Gambar 1. PAUD Sekato (Observasi awal) 
PAUD Sekato Kecamatan Minas Kabupaten Siak adalah merupakan salah satu wadah Pendidikan anak usia dini yang berada di tengah-tengah Desa Mandiangin, yang berdiri pada tahun 2008 terletak di jalan Utama Dusun Montikato, Desa Mandiangin berdiri di atas tanah dengan luas $6500 \mathrm{~m}^{2}$ dan luas bangunan $842 \mathrm{~m}^{2}$. Fasilitas yang dimiliki oleh PAUD Sekato terdiri dari 2 ruang kelas $(8 \mathrm{~m} \times 8 \mathrm{~m}), 1$ ruang guru $(4 \mathrm{~m} \times 8 \mathrm{~m})$, 2 kamar mandi $(2 \mathrm{~m} \times 3 \mathrm{~m})$, area outdoor, area terbuka untuk umum.

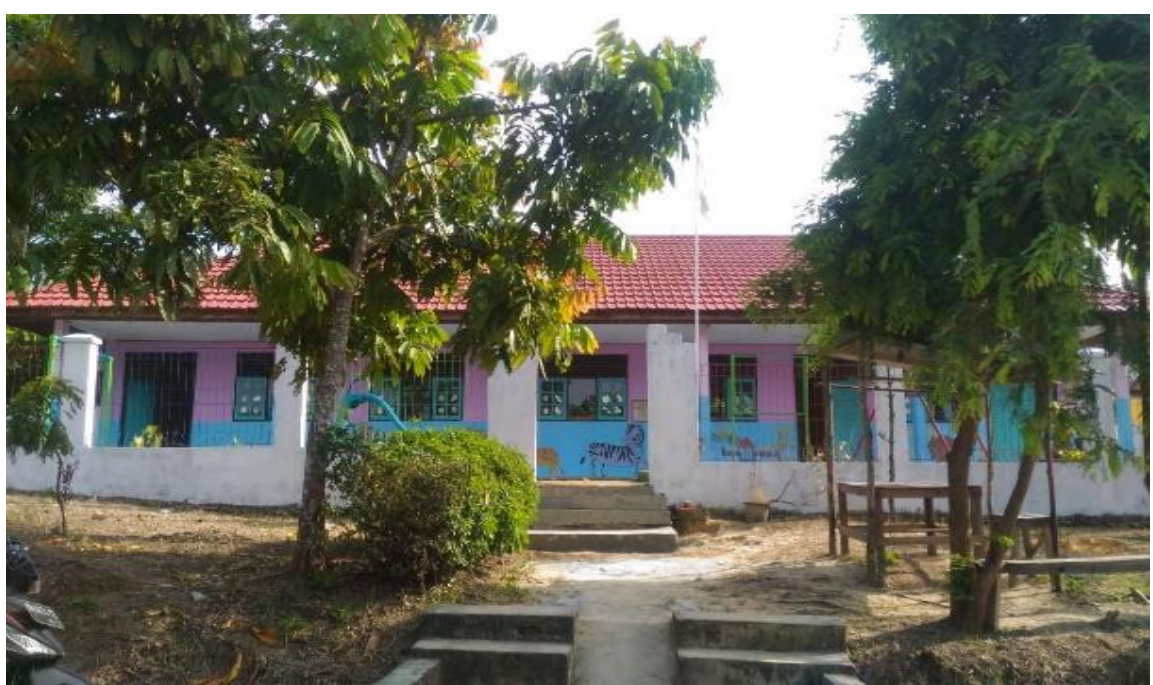

Gambar 2. PAUD Sekato (Desain oleh Tim KKN FAI UIR)

Bulan Juli 2019, tim mulai melakukan pendampingan penyusunan administrasi PAUD Sekato. Administrasi PAUD sebelumnya sudah ada namun masih sederhana, ada beberapa administrasi yang harus direvisi secara total. Komponen administrasi yang dikelola oleh pihak sekolah dan bekerjasama dengan tim, antara lain:

1) Administrasi umum

2) Administrasi personalia

3) Administrasi pembelajaran

4) Administrasi anak didik

5) Administrasi sarana prasarana

6) Administrasi keuangan

7) Administrasi hubungan masyarakat

Tim menyeleksi beberapa administrasi yang masih bisa digunakan dan dilanjutkan. Hasil seleksi mengungkapkan bahwa administrasi PAUD Sekato sudah bagus hanya perlu pembenahan dalam beberapa administrasi saja, terutama pada administrasi umum dan administrasi personalia. PAUD Sekato saat ini adminstrasi pembelajaran, anak didik, dokumen lembaga sudah sangat lengkap, yakni Prota, Prosem, RPPM, dan RPPH. Para guru sudah mengikuti pelatihan penyusunan administrasi pembelajaran yang diselenggarakan oleh pihak HIMPAUDI kecamatan dan kabupaten. 


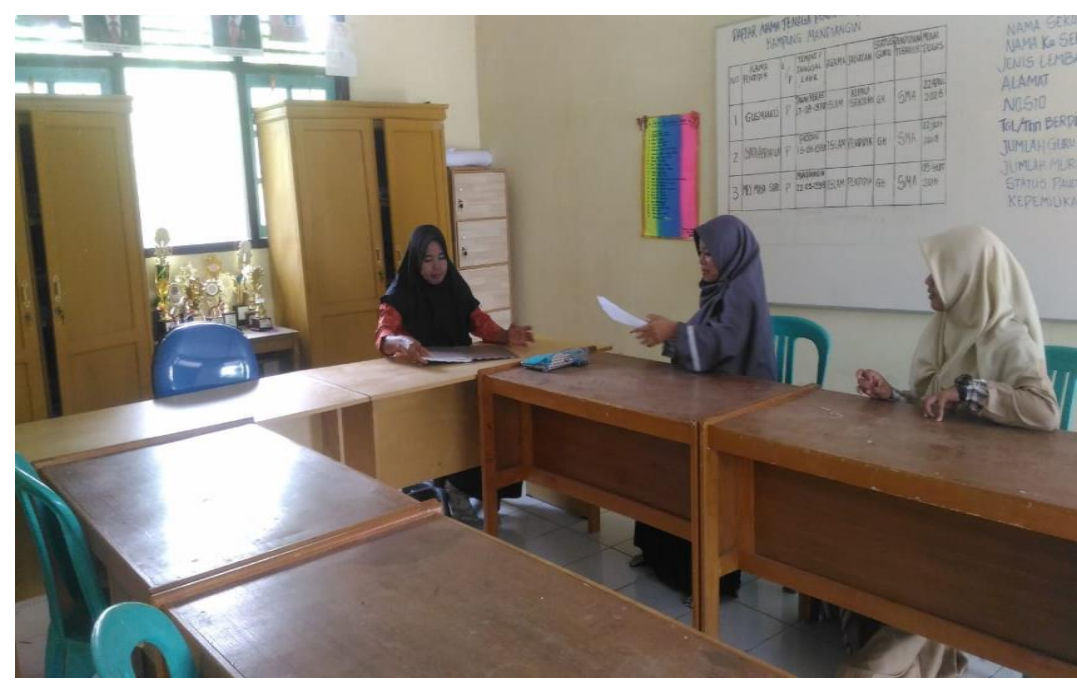

Gambar 3. Pendampingan Penyusunan Administrasi PAUD Sekato

Adminstrasi keuangan tidak dilakukan perubahan karena PAUD Sekato tidak menerima pembayaran spp tiap bulan dan honorarium guru diterima dari Pemerintah daerah tiap 3 bulan sekali. Dengan demikian tim hanya fokus pada administrasi umum saja. Tim telah melakukan pembenahan secara keseluruhan pada administrasi umum dengan cara menyusun ulang pembukuan. Untuk mempermudah kerja para guru selanjutnya, tim juga memberikan bantuan mesin printer.

Harapan tim untuk program selanjutnya adalah fokus pada administrasi sarana dan prasarana serta administrasi hubungan masyarakat. Tanggapan mitra sangat luar biasa, para guru bersemangat kembali unuk mengelola PAUD, bahkan berharap kepada tim untuk dapat mendampingi pihak sekolah dalam persiapan akreditasi PAUD Sekato.

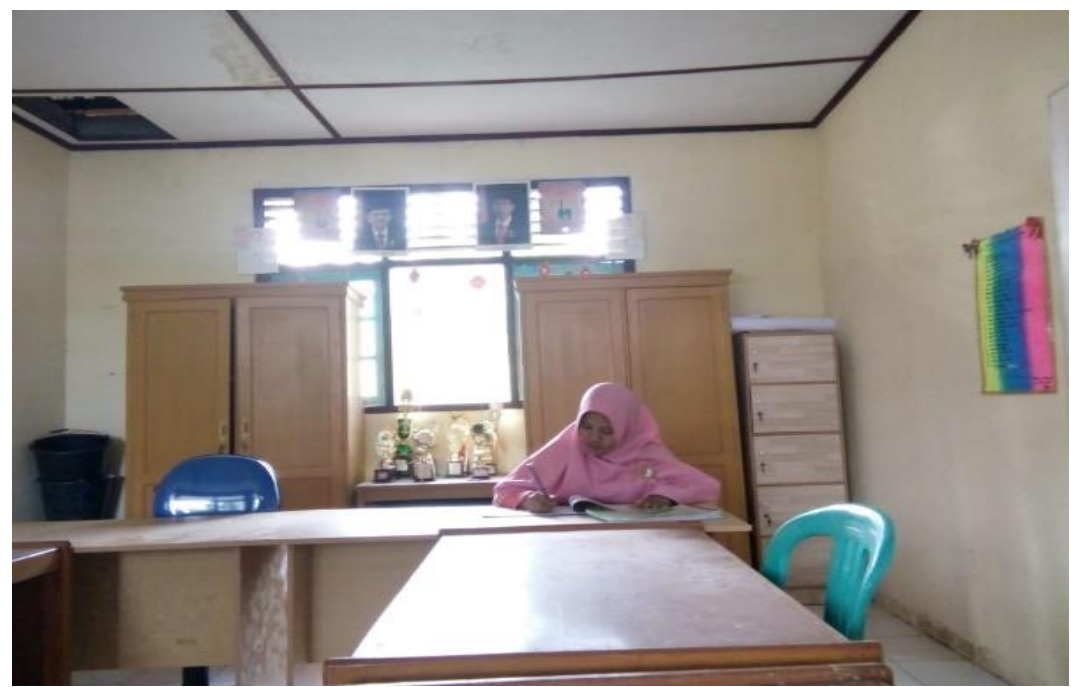

Gambar 4. Penyusunan Administrasi PAUD Sekato 


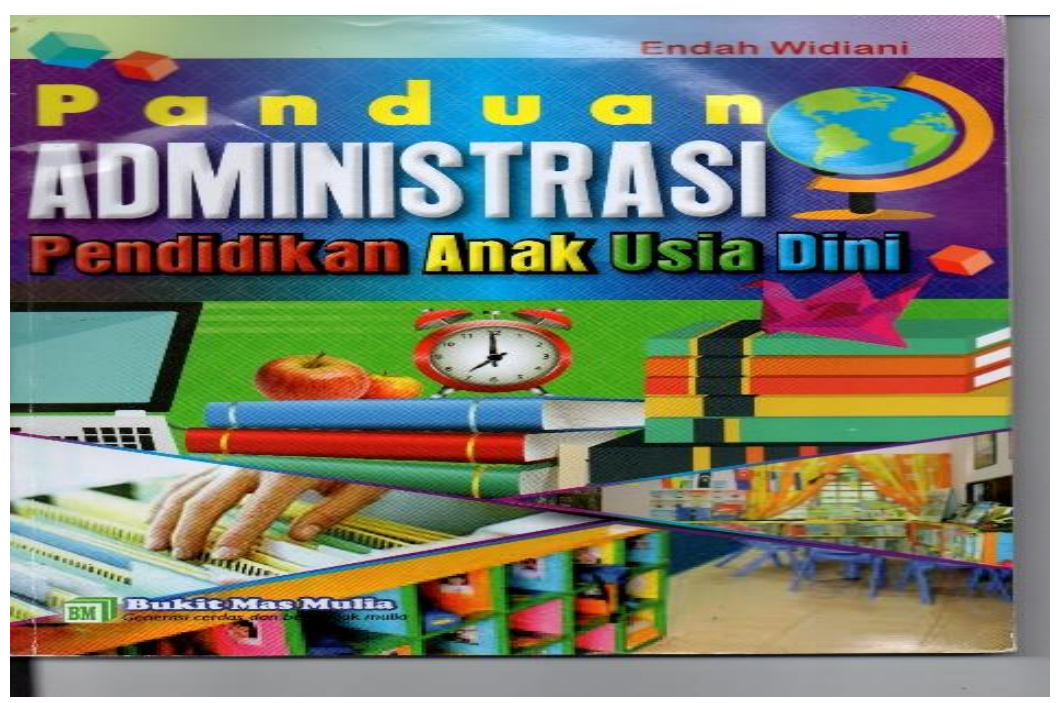

Gambar 4. Buku Perdoman Administrasi PAUD

\section{SIMPULAN}

Kesimpulan dari kegiatan ini adalah penyusunan administrasi PAUD Sekato Desa Mandiangin hanya fokus pada administrasi umum, administrasi pembelajaran dan administrasi peserta didik. Keterbatasan pendampingan ini dikarenakan waktu, jarak dan dana yang tersedia. Harapan tim untuk program selanjutnya adalah menyusun program administrasi yang belum terselesaikan agar administrasi PAUD Sekato tersusun lengkap dan dapat diajukan dalam pengajuan akreditasi PAUD.

\section{Ucapan Terimakasih}

Ucapan terima kasih disampaikan kepada pihak PAUD Sekato yang telah memberikan kesempatan, waktu dan tenaganya dalam kerjasama ini hingga kegiatan dapat selesai dengan baik. Terima kasih juga disampaikan kepada Lembaga Penelitian dan Pengabdian Masyarakat (LPPM) Universitas Islam Riau yang telah memberikan bantuan dana hibah internal Tahun 2019 sehingga kegiatan ini dapat terlaksana dengan baik dan lancar. Tim PkM yang telah kompak bekerjasama menyelesaikan kegiatan ini.

\section{REFERENSI}

Agustina, S. (2010). Pengelolaan kegiatan pendidikan anak usia dini di pos PAUD "Teratai Indah" Pedukuhan Dabag Condong Catur Depok Sleman. Skripsi. Yogyakarta: Universitas Negeri Yogyakarta.

Kasrani. (2016). Evaluasi program pendidikan anak usia dini (PAUD). Manajemen Pendidikan, 25(2), 233-243.

Rochaety, E. (2012). Sistem informasi manajemen pendidikan. Jakarta: Bumi Aksara. 
Saputra, E. D. (2016). Pengelolaan program pendidikan anak usia dini di PAUD Al-Ikhwan Tahun Ajaran 2015-2016. Skripsi. Palembang. UIN Raden Fatah.

Susilo, S. (2016). Pedoman akreditasi PAUD. Jakarta: Bee Media Pustaka.

Widiani, E. (2016). Panduan administrasi pendidikan anak usia dini. Bogor: Bukit Mas Mulia.

Wijayanti, W. (2008). Peran pengelolaan pendidikan di taman kanakkanak. Fondasia, 1(9), 1-12.

\section{Copyright and License}

This is an open access article distributed under the terms of the Creative Commons Attribution 4.0 International License, which permits unrestricted use, distribution, and reproduction in any medium, provided the original work is properly cited. (C) 2020 Ida Windi Wahyuni, Ary Antony Putra. 